\title{
Estudio de la metáfora en los ictiónimos de Canarias: una revisión actualizada con métodos terminológicos
}

\author{
ANA MARÍA MONTERDE REY \\ Universidad de Las Palmas de Gran Canaria
}

\section{INTRODUCCIÓN}

La pesca es un recurso primario en Canarias. A pesar de ello, hasta hace poco más de una década, los datos relativos a la biota marina se encontraban dispersos o no estaban actualizados (Consejería de Medio Ambiente y Ordenación Territorial del Gobierno de Canarias 2003). Sin embargo, en los últimos veinte años, debido a la potenciación de usos en el litoral y la creciente demanda social por conocer el entorno que nos rodea (ibid.), se han difundido varias obras y bancos de datos que recogen información sobre los peces de Canarias. Al tratarse de obras escritas desde un punto de vista científico, suministran datos de esta índole relativos a cada especie, si bien algunas de estas obras también proporcionan denominaciones vernáculas de peces en Canarias. Aun así la nomenclatura ictiológica es mal conocida (Alvar 1993: 185). No ha habido una colaboración entre ictiólogos y lingüistas, por lo que encontramos incoherencias tanto en los libros de ictiología como en los repertorios lexicográficos de esta materia. Además, la recogida de material lingüístico de esta índole es difícil:

\section{[...] por la del mundo al que nos asomamos; por el enmarañamiento de una termi- nología en la que no llegan a concordar los intereses del naturalista y los del pes- cador; por tratarse de campos semánticos muy próximos que van forzando los des- plazamientos semánticos de los significantes. (Alvar 1993: 185)}

Ante esta dificultad, nos dispusimos a efectuar una investigación para realizar una revisión completa y actual de los nombres vernáculos de los peces en Canarias, aunque no determinaremos si su formación ha tenido lugar en nuestras islas o proceden del español general o son de otro origen. Para ello, hemos efectuado un vaciado de obras de relevancia escritas en los últimos quince años y que contienen nombres comunes de los peces de Canarias. Dado el gran número de especies cuya denominación ha surgido en relación con una metáfora, vamos a centrarnos en la creación metafórica en los ictiónimos de Canarias y a compararla con estudios anteriores de esta índole. Antes de entrar en nuestra investigación, sin embargo, repasaremos la evolución del estudio de la ictionimia en Canarias.

Por tanto, con nuestra investigación pretendemos, por una parte, construir un listado actual de las denominaciones de los nombres vernáculos de los peces en Canarias y, por otra, entender mejor la gran riqueza de la creación metafórica de nuestra variedad dialectal de Canarias. Es decir, realizaremos un estudio lexicográfico y metafórico. 


\section{ESTUDIOS DE ICTIONIMIA EN CANARIAS}

Como los nombres de los peces tienen interés tanto para ictiólogos como para lingüistas, dividimos este estudio en dos partes: la primera presenta las obras que tratan la ictionimia desde un punto de vista lingüístico, y la segunda, las publicaciones científicas relevantes, propiamente ictiológicas, que incluyen nombres vernáculos de Canarias.

\subsection{Ictionimia de Canarias en publicaciones lingüisticas}

El primer autor en realizar una obra lexicográfica sobre historia natural de Canarias es el historiador Viera y Clavijo, quien en 1799 publica su Diccionario de Historia Natural de Canarias ${ }^{1}$. A pesar de denominarse diccionario, tiene más carácter de enciclopedia dada la inclusión de descripciones (Alvar 1977: 235), y en él aparecen tan solo 100 especies distintas de peces entremezcladas, por orden alfabético, con otros animales, plantas y minerales. Las entradas están organizadas por solo un nombre vernáculo del animal, seguido entre paréntesis del científico, una descripción del ser vivo y el origen de las denominaciones comunes. Precisamente en este origen etimológico comete errores (Alvar 1993: 304), pues no le respalda una investigación científica lingüística de la categoría que se podría llevar a cabo hoy en día. Otro punto débil de esta obra es que no encontramos todos los nombres vernáculos posibles para cada pez en cada entrada. Si un pez recibe más de un nombre común, simplemente aparece esa denominación en el diccionario en la letra correspondiente y hace referencia con la palabra véase a su equivalente en el diccionario. Al final de él se incluye un listado de todas las entradas y aquí sí se facilitan las posibles denominaciones en nombre vernáculo de cada pez. Asimismo, hay un índice alfabético dividido por seres vivos, en el que los nombres de los peces aparecen junto con los mariscos. En este índice se muestra el nombre común seleccionado para la entrada, seguido de su correspondiente científico. Desde el punto de vista lingüístico, habría sido más enriquecedor proporcionar aquí todos los nombres comunes vernáculos correspondientes a cada científico.

En 1968, Alvar, en su primer volumen de Estudios Canarios, presenta dos investigaciones sobre ictionimia. Con tal fin, realiza una encuesta con 248 preguntas relativas a peces, moluscos y crustáceos a dos trabajadores de la mar (1968: 43-55). La investigación consistió en enseñar a marineros una serie de fotografías y dibujos de estos seres vivos para que dijeran su nombre. Solo coincidieron en 133 denominaciones, si bien las divergencias se producen en la designación de seres marinos poco conocidos en la pesca local. Quizá el uso de láminas fue la causa de estas diferencias, dado que los pescadores no eran capaces de identificar algunas especies al carecer los dibujos de color y perder la dimensión y el volumen.

En otro capítulo, Alvar recoge la ictionimia del Scarus cretensis (1968:121-128), conocida como vieja en Canarias. En él trata con profundidad el origen de esta denominación desde los primeros documentos escritos por Aristóteles y Plinio sobre esta especie.

\footnotetext{
${ }^{1}$ Se han hecho cuatro ediciones: 1866, 1942, 1982 y 2005. Hemos manejado la de 1982.
} 
En el segundo volumen de Estudios Canarios, Alvar (1993) estudia la ictionimia de Canarias en tres capítulos. En el primero, investiga (1993: 177-188) la etimología del nombre vernáculo tollo, empleado para varias especies de escualos, y de su interferencia con el nombre tonina que denomina a especies de delfines. En otro capítulo (1993: 185-205), trata varias designaciones románicas para los escualos (hanequín, janequín, etc.) a través del mito de la Maisnie Harlequin. En un capítulo posterior (1993: 207259), indaga en el origen de los nombres de los peces según la lengua de procedencia: bereberismos, lusismos, americanismos y pseudoamericanismos, andalucismos, catalanismos, vasquismos y creaciones regionales. Esta parte del capítulo es una repetición de una publicación de 1975. En él Alvar estudia la terminología canaria de los seres marinos a partir de encuestas in situ que consisten en 175 preguntas en relación con los conocimientos de los pescadores. Solo recoge los nombres que presentan posibilidades de caracterizar el léxico marinero de Canarias desde el punto de vista de sus peculiaridades. Como nombres de especies procedentes del beréber determina cuatro: tabaga, baybay, tabaque, tasarte. Lusismos: abade, abae, malfara, fula, chopa, bicuda, pallete, quella, alfonsiño, alfunsiño, alcatriña, funsiño, caboso, saifila, seifio/a, quelme, brota, cherne, cherna, maju(g)a y acaso zapata. Americanismos y pseudoameriscanismos: guachinango, peto y picuda. Andalucismos: aguja paladar, buyón, verrugato o verrugate, cornivate, espadarte, jaquetón, jaqueta, jurel, boquerón, maroma, robalo, salema, melva y quizá albajar. Catalanismos: anjova y rascae. Vasquismos: tollo y guelde. Como creaciones regionales, Alvar señala: calé, chamorrito, lebrancho, lebranche, labranche, galupe, galúa, medregal, pedregal, bredregal, rabil y sarasa.

En 2005, Machado Carrillo y Morera Pérez, con el aval de la Academia Canaria de la Lengua, publican una obra que intenta normalizar los nombres comunes de los animales y las plantas de Canarias. Como se indica en su prefacio, es un catálogo técnico en el que se ha seleccionado un único término para nombrar en la lengua común, de manera unívoca cada especie que contiene, con el objetivo de fijar un nombre de uso general para toda la región y así evitar las lógicas confusiones que se producen por la multitud de nombres vulgares. Registran 354 especies de peces y cada entrada está constituida por el nombre latino del animal seguido de una única denominación común en Canarias. Contiene dos índices alfabéticos, uno organizado por el nombre científico y otro por el común, que constituye la única información aportada. Para seleccionar una única denominación común, la Academia ha contado con un nutrido grupo de expertos que han seguido los mismos criterios.

\subsection{Ictionimia de Canarias en publicaciones científicas ictiológicas}

Las publicaciones ictiológicas sobre Canarias comienzan con Cuvier y Valenciennes (1828-1849) en el siglo XIX. Sin embargo, no es hasta principios de los años 90 del siglo XX, cuando el nombre vernáculo de Canarias empieza a adquirir importancia en obras ictiológicas. De entre todas las publicaciones, destacamos las siguientes ${ }^{2}$.

\footnotetext{
${ }^{2}$ Estas obras han sido recomendadas por los catedráticos Pedro Sosa Henríquez y José María Lorenzo Nespereira, pertenecientes al grupo de investigación mencionado en la nota VII y expertos en ictiología.
} 
Franquet Santaella (1995) presenta una obra de especies de interés pesquero de Canarias que se ocupa de 132 peces. Cada entrada consta del nombre científico y los nombres dados en Canarias bien documentados por encuestas a pescadores. Al tratar solo especies de interés pesquero, la cantidad de nombres vernáculos es muy inferior a obras y bases de datos posteriores, que abarcan también especies no destinadas a la pesca.

González Jiménez et al. (2000) son pioneros con una guía submarina de 126 peces de Canarias. Está organizada onomasiológicamente por peces cartilaginosos y óseos y, dentro de cada categoría, por las clasificaciones científicas: órdenes, familias y especies. La entrada está encabezada por los nombres vernáculos de Canarias junto con el correspondiente científico. Los nombres están bien documentados, pero, como la obra no ha sido escrita por lexicógrafos, se comente el error de escribir las denominaciones con la inicial mayúscula e incluso a veces en plural.

Brito Hernández et al., en 2002, divulgan un catálogo de peces de las islas Canarias con 85 especies de peces cartilaginosos y más de 600 de peces óseos. Las especies están clasificadas por órdenes y familias, por lo que la ordenación es onomasiológica. Cada entrada incluye el nombre científico y los nombres vernáculos de Canarias. Se trata de una obra de gran rigurosidad desde el punto de vista de las denominaciones vernáculas y es, además, la que abarca mayor número de ejemplares.

Hanquet (2004) ilustra una guía con 100 peces de Canarias. De nuevo, la cantidad de peces es inferior a otras obras. En esta, además, el nombre vernáculo de Canarias no se destaca en la ficha de cada especie, sino que se lista al final del documento con el número de página correspondiente del pez y solo se facilita una denominación por especie. Además, no se precisa de dónde se han obtenido los nombres comunes. $\mathrm{Su}$ interés para la ictionimia de Canarias es, por tanto, escaso.

Por último, en 2011, el Ministerio de Medio Ambiente y Medio Rural Marino del Gobierno de España difunde el listado de denominaciones comerciales de especies pesqueras y de acuicultura admitidas en España. Se proporcionan tablas con los nombres científicos de las especies y sus equivalentes en lengua común en distintas Comunidades Autónomas, entre ellas Canarias.

En lo relativo a bases de datos, en Canarias contamos con PescaBase (2013) desde 2005, que gestiona tan solo 89 especies de interés pesquero en Canarias. En esta base de datos se puede buscar un pez por el nombre común, por el científico o por la ilustración. Una vez seleccionado el pez buscado, aparece una amplia ficha que cuenta con los nombres comunes dados en Canarias.

A nivel internacional tenemos Fishbase (2013), que es, según los ictiólogos, la base de datos de peces más completa que existe. Ha sido desarrollada por el International Center for Living Aquatic Resources Management con la ayuda de 1920 colaboradores. Permite realizar búsquedas por nombre vernáculo, nombre científico, zona geográfica, familia, o ecosistema. Incluye 546 especies en Canarias y, curiosamente, en muchas de ellas se indica el nombre vernáculo en nuestras islas, pero no en el de otras comunidades autónomas españolas. Abarca 32400 especies distintas a las que les corresponden 298800 nombres vernáculos. 
Al no intervenir lexicógrafos o terminógrafos en la elaboración de todas estas obras, se han cometido errores. Así, los nombres comunes se han escrito con la inicial mayúscula en todos ellos, menos en los documentos de Hanquet y del Ministerio de Medio Ambiente y Medio Rural Marino, en los que las denominaciones aparecen con todas las letras en mayúscula. Lo correcto es que se escriban en minúscula, a no ser que una regla ortográfica indique lo contrario, como se aconseja en la elaboración de herramientas terminográficas (Arntz y Picht 1995: 202).

\section{Metodología}

Describimos a continuación nuestra muestra, el instrumento de recogida y el procedimiento de análisis de datos.

\subsection{La muestra}

En Canarias existen unas 144 especies de interés pesquero (Consejería de Agricultura, Ganadería, Pesca y Aguas del Gobierno de Canarias 2012). Como nuestro trabajo pretende efectuar una revisión actualizada de las denominaciones vernáculas en Canarias, no nos hemos limitado solo a las especies de interés pesquero, sino que hemos abarcado hasta 737 peces. Estas especies han sido todas las halladas en fuentes recomendadas por biólogos expertos en ictiología de Canarias ${ }^{3}$ publicadas en los últimos quince años ${ }^{4}$. Asimismo, hemos incluido dos importantes bancos de datos: Pescabase y Fishbase. Todos estos documentos han sido ya comentados en el epígrafe 2.2.

De las 737 especies de peces que hemos aislado, 279 especies cuentan con nombre común en Canarias y el resto solo con nombre científico. En total hay 452 nombres vernáculos ${ }^{5}$ distintos, de los cuales $366(80,97 \%)$ se han formado por metáfora y los 85 restantes, no. De estos 85, 27 nombres están compuestos por dos elementos léxicos, de los que uno de ellos es metafórico. Por tanto, si sumamos estos 27 nombres con los 366 , la metáfora en los ictiónimos de Canarias ascendería a 86,94 \% en la creación de nombres, un porcentaje alto que justifica el interés de nuestro estudio.

En ninguno de los documentos de vaciado se especifica qué nombres han sido creados en Canarias y cuáles provienen del español general, por lo que esto sería parte de un estudio posterior que aquí no podríamos abarcar.

Nos hemos decantado por estudiar nombres hallados en obras escritas y no por los nombres «vivos» empleados por los trabajadores de la mar por dos motivos. Uno es la complejidad ya denunciada por Alvar (1968: 43-55) en la recogida de estos datos, pues a los pescadores les es difícil identificar una especie por su fotografía o dibujo. Otro es la divergencia que existe en este sector en el que un pescador de un puerto puede llamar de una manera a un pez y otros de otros puertos identificarlo por nombres distin-

\footnotetext{
${ }^{3}$ Véase nota 7.

${ }^{4}$ Brito Hernández et al. (2002) y González Jiménez et al. (2000).

${ }^{5}$ Son 622 nombres vernáculos, pero 169 están repetidos. Por ejemplo, abade es el nombre de dos especies, aguja el de siete, agujón el de dos, etc.
} 
tos. Incluso dentro de un mismo puerto, hay contradicciones entre los pescadores. Todo esto supone un maremágnum de difícil ordenación.

Además, al estudiar distintas obras escritas, podremos constatar, en futuras investigaciones, si existen incoherencias tanto en los libros de ictiología como en los repertorios lexicográficos de esta materia (Alvar 1993: 185).

\subsection{Instrumento de recogida de la muestra}

Hemos decidido que en un trabajo lexicográfico de este tipo, lo más adecuado era aplicar un método terminológico: un método onomasiológico; es decir, hemos partido del concepto para llegar a los términos y palabras que los representan lingüísticamente. Hemos efectuado el vaciado de los nombres comunes de Canarias hallados en las fuentes relacionadas en el epígrafe 3.1. mediante la realización de un sistema de conceptos con todas las especies encontradas en las fuentes recomendadas ordenadas onomasiológicamente por la clasificación científica: superclase, clase, subclase, superorden, orden, familia y especie. Hemos introducido toda esta ordenación en el programa informático GeneSis, generador de sistemas de conceptos creado por la autora de este artículo (véase Monterde Rey, 2005, 2006 y 2011). Para el nombre de las especies hemos seleccionado el nombre científico, pues es internacional y normalmente unívoco. Además, hay especies que solo cuentan con esta denominación. En la figura 1 mostramos un extracto del sistema de conceptos.

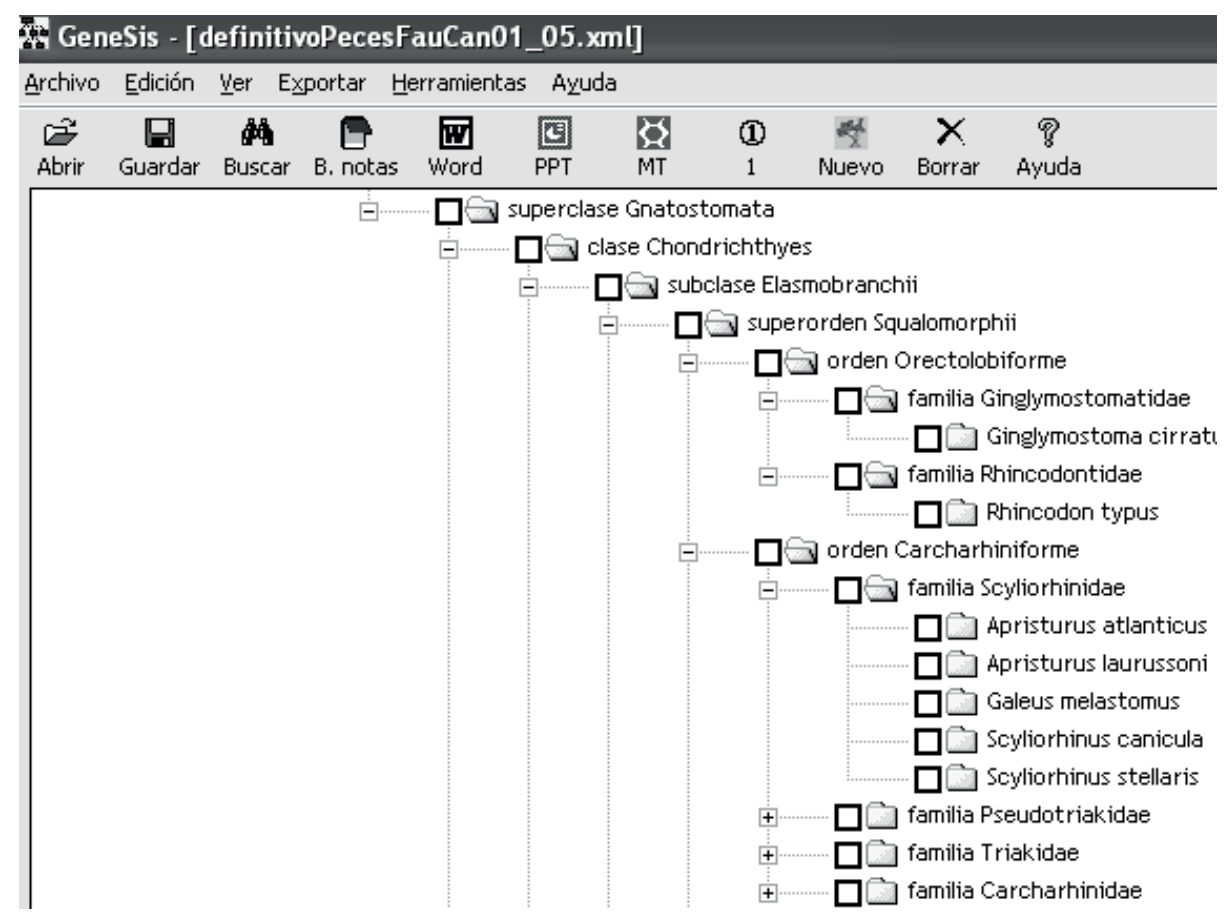

Figura 1. Extracto de sistema de conceptos de peces de Canarias en GeneSis 
Una vez terminada la ardua labor de clasificar todos los peces de Canarias encontrados en las fuentes de nuestro estudio, gracias a una función de GeneSis, hemos podido exportar de forma automática e inmediata todos los nombres científicos de las especies al programa informático MultiTerm, uno de los principales gestores de bases de datos terminológicos. Luego, a cada entrada le hemos añadido manualmente, si existían, sus equivalentes empleados en el español de Canarias hallados en las fuentes de trabajo, las fuentes de donde se ha extraído ${ }^{6}$ cada uno de los nombres vernáculos y la categoría de la metáfora a la que pertenece, si es un nombre formulado por este procedimiento. Además, hemos ilustrado cada ficha con una fotografía para encontrar sentido a la denominación por metáfora. Estas fotografías han sido adquiridas a la empresa Oceanográfica gracias a una dotación económica obtenida en un proyecto de investigación ${ }^{7}$. La inclusión de todos estos campos nos permite explotar al máximo la muestra para nuestros objetivos.

Veamos aquí un ejemplo de entrada de la especie Sparisoma cretense.

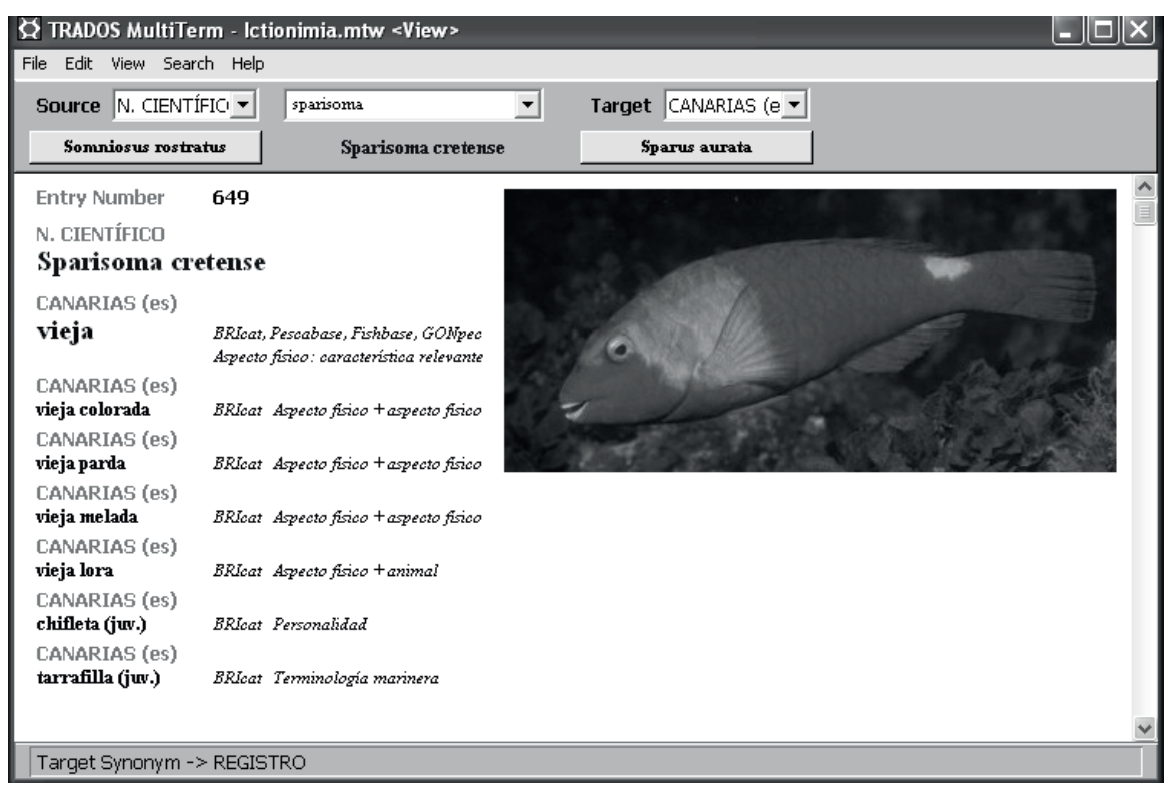

Figura 2. Ejemplo de entrada de una ficha terminológica en MultiTerm

Como podemos observar en su ficha, Sparisoma cretense recibe en Canarias siete denominaciones comunes diferentes. Todos estos nombres han sido hallados en Brito Hernández et al. (2002), que hemos abreviado BRIcat. La denominación vieja ha sido

\footnotetext{
${ }_{7}^{6}$ Hemos empleado abreviaturas para los libros. En concreto, hemos usado la de la signatura topográfica.

${ }^{7}$ Proyecto «Estudio de la terminología de la flora y fauna marina de Canarias: elaboración de una base de datos terminológicos y un diccionario bilingüe (español-inglés)». Financiado con por el Vicerrectorado de Investigación, Desarrollo e Innovación de la Universidad de Las Palmas de Gran Canaria, para su ejecución en un año desde el 1 de enero de 2004. Ref. UNI2003/14. Investigador principal: Dra. Ana María Monterde Rey.
} 
encontrada, además, en Fishbase, Pescabase y en González Jiménez et al. (2000), abreviado GONpec. A cada nombre se le da una etiqueta del tipo de metáfora al que pertenece según nuestro estudio. Así, por ejemplo, la mencionada vieja sería una metáfora relativa a aspecto físico.

\subsection{Análisis de datos}

Para el análisis de datos nos hemos beneficiado de los parámetros de búsqueda de $\mathrm{Mul}$ tiTerm. Gracias a ellos, hemos podido aislar todos los nombres creados por un determinado tipo de metáfora y agruparlos en las distintas categorías halladas. Como hemos descrito en el epígrafe destinado a la muestra, contamos con 85 nombres que no se han formado por metáfora y 366 que sí se han creado por este procedimiento. Como uno de los objetivos de nuestro trabajo era proporcionar una relación actual de las denominaciones de los nombres vernáculos en Canarias, listaremos y analizaremos primero estos 85 que no se han formado por metáfora. De estas 85 denominaciones «no metafóricas», 27 están compuestos por dos elementos léxicos, de los que uno de ellos es metafórico. Escribimos en negrita la parte de los nombres compuestos que sí se haya construido por metáfora.

Por último, para el análisis de las denominaciones surgidas por metáfora, las agruparemos en categorías. Proporcionaremos los nombres de todos los peces contenidos en cada una, pero, por razones de espacio, no mencionaremos los nombres científicos de las especies a las que corresponden. Por el mismo motivo, en los grupos con un elevado número de denominaciones, tampoco comentaremos una por una, sino que daremos normas generales de las que facilitaremos ejemplos y trataremos los casos problemáticos. Si para justificar la metáfora tenemos que proporcionar la etimología de algún nombre, emplearemos, por razones obvias de prestigio, el Breve Diccionario etimológico de la lengua castellana de Coromines (2009) y, si no existe en él una entrada, el Diccionario de la Real Academia de la Lengua Española en línea.

Dentro de cada categoría de metáfora estableceremos una división en nombres simples y compuestos o mixtos; esto es, denominaciones formadas por más de una palabra. No vamos a incluir subcategorías dentro de los nombres mixtos para no atomizar tanto el listado. Es decir, por ejemplo, dentro de aspecto físico + personalidad, no vamos a incluir aspecto físico por color + personalidad positiva, aspecto físico por característica destacada + personalidad positiva, etc.

Por último, queremos añadir que si un nombre comienza por la palabra pez o peje, no lo hemos considerado como compuesto.

\section{Resultados}

El mar y la tierra: Un mundo se trasplanta, aunque sólo sea parcialmente, a otro mundo. El hombre habita en la tierra; sus salidas al mar son siempre para volver, por ello se lleva en su barca el léxico que aprendió en la casa. Al hallarse con nuevas realidades necesita nombrarlas, y los nombres que da son aquellos que ya conocía, y que diariamente afloraban a sus labios: las motivaciones para dar esos nombres son múltiples [...], la forma, el color, una comparación, etc. La efectividad, la imaginación y la fantasía están actuando vivamente, por más que muchas veces nos olvidemos de ello. El mundo metafórico es de una portentosa riqueza (Alvar 1977: 237-238). 
En nuestro estudio mostraremos esta portentosa riqueza.

\subsection{Nombres comunes no metafóricos}

Hemos hallado 85 denominaciones que no se han originado por metáfora. Se trata de las siguientes: alacha, albacoreta, albajar, albafara, anchoa, anjova, aquella, arenque, atún, atún sahariano, bacoreta, barraco, besugo ${ }^{8}$, besuguito, bica, breca, breca colorada, briota, carite, cherna, cherne, cherne moruno, chicharro ${ }^{9}$, chopa, chopa perezosa, chopón, congrio, congrio negro, congrio picopato, corrigüelo, escojinobo, garapello, laureana, linguirón, longarón, macho de salema, majuga (juv.) $)^{10}$, marfara, medregal, medregal negro, merluza, merluza canaria, merluza de hondura, merluza del país, mero, mero americano, mero negro, murión, murión-morena verde, pallete, palluda, paparda, pargo, pargo americano, pargo macho, quella, quelme, quelmín, rape, rayela, sábalo, salema, salmón, salmón de alto, salmón de hondura, salmonete, sardina, sardina arencada, sardina de ley, sardina listada, sargo, sargo blanco, sargo breado, sargo briao, sargo molinero, sargo molino, sargo picudo, seifio/a, sinobiel, tabaga, tabeque, tasarte, tiburón azul, tiburón ballena, tiburón tigre.

Como se puede comprobar, de estas denominaciones, 27 están compuestas por dos unidades y una de ellas es metafórica.

Once hacen referencia al aspecto físico: colorada, negro, picopato, morena verde, arencada, listada, blanco, breado, briao, picudo, azul.

Como veremos en el estudio que describimos a continuación, el aspecto físico es la metáfora más recurrente.

Seis se refieren a la procedencia: sahariano, canaria, de hondura, del país, americano, de alto.

Dos, a nombre de animales: ballena, tigre.

Uno, a personalidad: perezosa.

Uno, a edificio: molino.

Uno, a etnia: moruno.

Uno, a sexo: macho.

Uno, a rango: de ley

Uno, a actividad humana: molinero.

${ }^{8}$ De origen incierto, quizá procedente del occitano bescu(o) o besugue 'bizco', por los ojos abultados del besugo; besuc parece ser hermano del castellano anticuado bisojo 'vizco' (donde bis- prefijado a ojo, indica, como suele, imperfección), levemente alterado por influjo de caluc 'miope'. (Coromines 2009: 74).

${ }^{9}$ Podría proceder de chicharra, pero según Coromines (2009: 173) es una voz de la costa atlántica de España y Portugal, desde el País Vasco hasta Canarias y Cádiz; de origen incierto.

${ }^{10}$ Emplearemos esta abreviatura cuando un nombre denomine solo los ejemplares juveniles. 


\subsection{Nombres metafóricos}

De los 366 nombres que se han generado por metáfora, tenemos las siguientes categorías: aspecto físico/parte del cuerpo (91 denominaciones), animales (81 denominaciones), objetos (66), personalidad (51), profesiones/ actividades humanas (27), nombres de persona (15), plantas (7), terminología marinera (5), estado civil/sexo (5), lugar de procedencia (5), religión (4), mundo celeste (3), frutas (2), sabor (2), órgano sexual (1) y parentesco (1). De cada categoría, además, hay nombres mixtos; es decir, denominaciones compuestas por dos elementos léxicos de los que uno se ha formado atendiendo a una categoría, y otro, a otra. Veamos estos datos numéricos de forma gráfica.

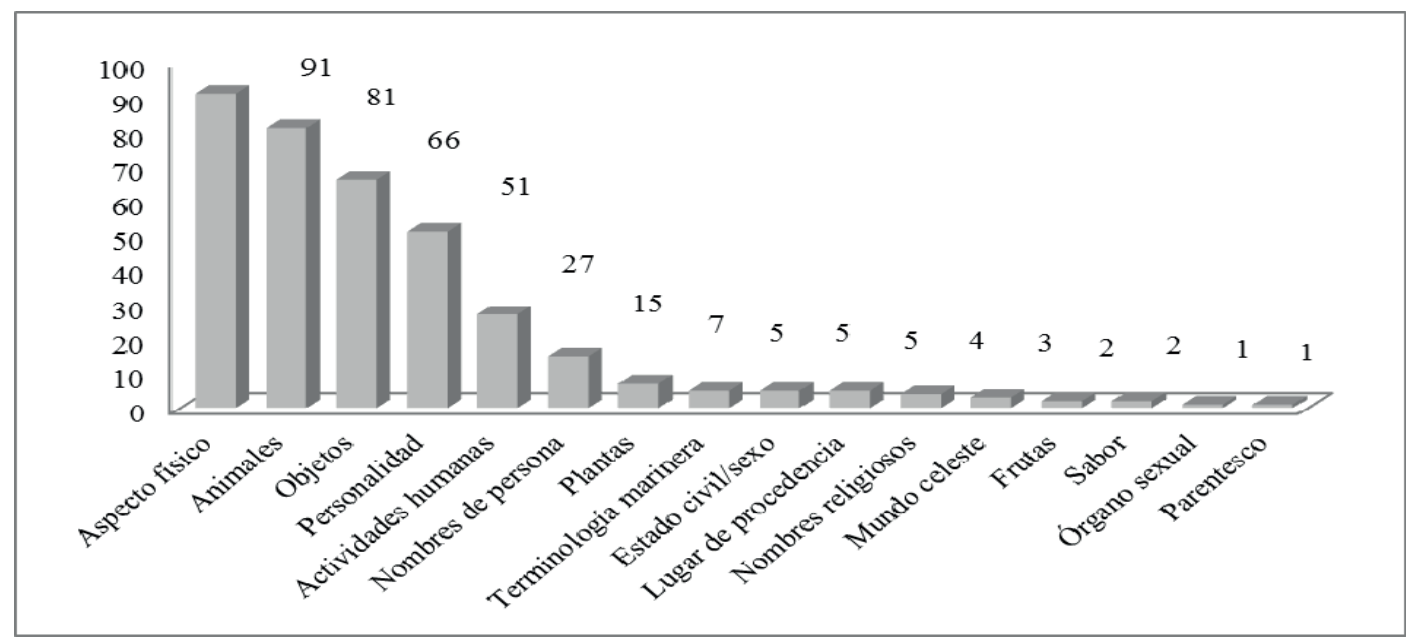

Diagrama 1. Metáfora en los nombres vernáculos de los peces en Canarias

A continuación vamos a mostrar los resultados de cada una de estas categorías por orden de abundancia.

\subsubsection{Metáfora de aspecto físico/parte del cuerpo}

El mayor número de denominaciones se encuentra bajo la categoría de aspecto físico. No es de extrañar que sea así, pues al marinero o al pescador le es fácil identificar un pez por su descripción física, por algo que destaque en su aspecto. Así encontramos 91 denominaciones, 60 puras, es decir, constituidas por un solo nombre, y 31 mixtas, esto es, compuestas por dos unidades. De las 60 simples hemos hallado las que mostramos a continuación:

Cuarenta y una denominaciones que tienen que ver con una característica física relevante del animal en general, o de una parte del animal: barbudo, barriguda, bicuda ${ }^{11}$, boga ${ }^{12}$, bonito, boquerón, cabezote/cabesote, carita, chamorro ${ }^{13}$ (juv.), coleto ${ }^{14}$, cornu-

\footnotetext{
${ }^{11}$ De picuda. Lusismo (Alvar 1975: 433)

${ }^{12}$ Del latín boca.
} 
da, corva ${ }^{15}$, dientón, empedrado, filudo, galletón ${ }^{16}$ (juv.), lamoso ${ }^{17}$, lenguado, lisa, lisote, listado, moñuda, morruda, ojochicle, ojo de piedra, palometa ${ }^{18}$, palometón ${ }^{19}$, papuda, patudo, pejerrabo, picopato, picuda, picudo, picuillo, pinchudo, rabil, rayado, remudo, seboburro, serruda (juv.), vieja.

Diecisiete denominaciones relativas a color, tanto para el color del pez al completo como para el color de una parte del animal: amarillo, baila ${ }^{20}$, blanquilla, boca de oro, bocanegra, bocinegro, colorado, dorada, dorado, maroma ${ }^{21}$, morena, negrito, negrón, pejeverde, pinto, rubio y tintarroja.

Dos con referencia a raza o etnia: calé, gitano.

En cuanto a los nombres compuestos, tenemos los 31 siguientes:

Diecisiete que combinan aspecto físico + aspecto físico: bonito listado, colorado anchete, lenguado doble, lenguado manchado, lenguado pintorriado, lisa amarilla, morena lamosa, morena negra, morena papuda, morena pintada, morena verde, palometa negra, remudo blanco, remudo rasposo, vieja colorada, vieja melada, vieja parda.

Diez, aspecto físico + lugar procedencia: barriguda de hondura, bonito del norte, caboso ${ }^{22}$ de hondura, caboso de las cuevas, caboso de los charcos, morena de hondura, papudo de hondura, papudo de tierra, rubio de hondura, rubio de poco agua.

Dos, aspecto físico + etnia: barriguda mora, dientón angolés.

Dos, aspecto físico + animal: morena picopato, vieja lora.

Como podemos observar, todos los nombres son muy gráficos y, efectivamente, en la realidad hacen honor a su nombre. Así, por ejemplo, la especie reconocida por el

\footnotetext{
${ }^{13}$ Hasta 1350, 'que tiene la cabeza esquilada'. Origen incierto, probablemente del prerromano y con parentela en vasco (Coromines 2009: 16).

${ }^{14}$ Del it. ant. colletto 'vestidura de cuero que cubría pecho y espalda y se llevaba bajo la coraza', deriv. de collo 'cuello' (Coromines 2009: 138). Sin embargo, creemos que en caso de la denominación del pez hace referencia a la «cola», pues se trata de un tiburón que destaca por lo alargado del lóbulo superior de su aleta.

${ }^{15}$ Del latín curvus 'curvo' 'corvo', 'parte de la pierna opuesta a la rodilla, por donde se dobla y encorva' (Coromines 2009: 153).

${ }^{16}$ Según la Academia Canaria de la lengua (2013), se emplea en Gran Canaria y Tenerife para denominar a un adolescente o muchacho. Como este es el nombre que se emplea a un ejemplar juvenil de Pomatomus saltator/saltatriz, tiene mucho sentido que se use esta denominación.

${ }^{17}$ Que tiene o cría lama= cieno blando, suelto y pegajoso, que se halla en lugares del fondo del mar.

${ }^{18}$ Es alteración del gr. pelays, -ydos, ‘bonito' (Coromines 2009: 409). Sin embargo, Alvar Ezquerra (1977) lo señala como derivado de la palabra paloma.

${ }^{19}$ De palometa.

${ }^{20}$ Del latín varia 'de colores diversos, manchado'. Se llama así por los puntos negros de su cuerpo (cf. Veny 1993: 761-774).

${ }^{21}$ Según ha investigado Alvar (1975: 456-457), proviene del andalucismo mahoma. El canario cambió la h por la r y la introdujo en su vocabulario marinero. La mahoma es una raya de color negro, color con el que se asocia al profeta.

${ }^{22}$ Según Alvar (1993: 228), es un lusinatismo que viene dado por la desproporcionada cabeza que este pez tiene con respecto al cuerpo.
} 
nombre de bicuda es larga y puntiaguda, lo que le confiere aspecto de pico; el gitano y el calé son "morenos"; el pez moñuda tiene unas protuberancias en la cabeza que le hacen parecer que tiene un moño; el pinchudo es un tiburón cuyo conjunto de aletas parecen pinchos que sobresalen de su cuerpo, etc.

\subsubsection{Metáfora de nombres de animales}

Como señala Alvar (1993: 156), «las animalizaciones en lingüística han dotado de nuevas expresividades a las hablas populares de las Islas» Canarias. Precisamente el segundo mayor número de metáforas lo encontramos en esta categoría con un total de 81 , de los cuales 38 nombres proceden de la denominación de un animal terrestre, uno, de uno marino, y 42 son mixtos.

Los nombres relativos a animales terrestres son:

Dieciséis, a mamíferos domésticos: baqueta ${ }^{23}$, burrito, burro, caballa, cabrilla, cachorro (juv.); chucho ${ }^{24}$, conejo, gamela ${ }^{25}$, gata, pejecamello, peje cochino, pejepato, pejeperro, vaca, vaquita.

Nueve, a aves: alcatriña ${ }^{26}$, andoriñ $a^{27}$, corvina ${ }^{28}$, gallinita, gallito, gallo, galludo, melva ${ }^{29}$ y pejeáguila.

Seis, a mamíferos salvajes: lebrancho ${ }^{30}$, lubina ${ }^{31}$, pejerata o rata, ratón, zorro y robalo/róbalo ${ }^{32}$.

Tres, a insectos: araña, chicharra ${ }^{33}$ y mariposa.

Cuatro, a reptiles: culebra, jurel ${ }^{34}$, lagarto y pejesapo.

También hay un nombre que hace referencia a otro animal marino; se trata de bogavante.

En la categoría de mixtos hemos descubierto 42 denominaciones:

\footnotetext{
${ }^{23}$ Proviene de vaca (Alvar 1977: 237).

${ }^{24}$ Americanismo, 'tercianas' 'escalofrío', 'miedo'. Del quichua chuhchu 'tercianas'. Chucho 'perro' (Coromines 2009: 177).

${ }^{25}$ De gamella, del latín camella 'escudilla, gamella', derivado de camelus 'camello', por comparación de forma de la artesa invertida, o del arco del yugo, con la joroba de un camello (Coromines 2009: 268).

1. Escudilla. 2. Hembra de gamello (= camello) (Real Academia Española). En este caso, la coloración de este tiburón y las aletas dorsales que parecen jorobas, pueden haber generado esta metáfora relativa a la hembra del camello.

${ }^{26}$ Del portugués. De alcatraz y este probablemente del árabe gattâs (Coromines 2009: 19).

${ }^{27}$ De andorina, golondrina. Del lat. hirundo, -̌nis, infl. por andar (Real Academia Española).

${ }^{28}$ De corvino, cuervo. Del latín corvus (Coromines 2009: 163).

${ }^{29}$ De milano. Del latín miluus íd. Por extensión aplicado a un pez (Coromines 2009: 372).

${ }^{30}$ De liebre (Alvar 1975: 463).

${ }_{31}^{31}$ De lobina, derivado de lobo, 'pez'. Del latín lupus (Real Academia Española).

${ }^{32}$ Metátesis de *lobarro, derivado de lobo, que como el latín lupus 'lobo' se aplicó metafóricamente a este pez.

${ }_{33}^{3}$ De cigarra. Alteración del antiguo chicarro, 1495 (chicharra), es forma de origen mozárabe andaluza y toledana (Coromines 2009: 129).

${ }^{34}$ Del mozárabe $ұ \bar{u} r e \bar{l}$ o del catalán sorell íd., diminutivos del latín saurus íd., propiamente 'lagarto' (Coromines 2009: 325).
} 
Quince en las que se combinan animal terrestre + aspecto físico: berrugato/verrugato, burro listado, cabrilla negra, cabrilla pintada, cabrilla rubia, chucho amarillo, chucho negro, corvina blanca, corvina negra, gallo aplomado, gallo azul, gallo pinto, gallo plateado, gallo verde y pejeperro amarillo.

Nueve, animal terrestre + lugar de procedencia: águila de mar, araña de hondura, araña de poca agua, burro costero, burro de la costa, caballito de mar, cabrilla de fuera, cabrilla de tierra, lagarto de hondura.

Cuatro, animal terrestre + profesión/actividad humana: cabrilla melera, cabrilla reina, gallo barbero y lagarto capitán.

Cuatro, animal terrestre + etnia: caballa morisca, gallo moruno, gallo romano y jurel chino.

Tres, animal terrestre + rango: burrito de ley, gallito de ley y lagarto real.

Dos, animal terrestre + nombre religioso: conejo diablo y gallo de San Pedro.

Dos, animal terrestre + animal terrestre: burrogato y gallo cochino.

Tres, animal terrestre + objeto: cabrilla ruana ${ }^{35}$, gallo escopeta y gata tramolla ${ }^{36}$.

Todos estos nombres en el fondo hacen referencia a la apariencia física del pez, pues se le nombra por su semejanza con otro animal bien en su aspecto general o en una de sus partes. Por ejemplo, baqueta es el nombre de dos especies que tienen el colorido blanco y negro a parches de las vacas lecheras; la corvina es negra como un cuervo, etc. En el caso de las denominaciones compuestas, las que podrían ofrecer alguna duda son aquellas cuyo segundo nombre se refiere a una actividad humana y a un nombre religioso, metáforas que pueden explicarse de la siguiente forma.

El lagarto capitán está siempre vigilante, como un capitán; la cabrilla reina tiene bellos colores, por lo que se la podría considerar una "reina" del mar; el gallo barbero tiene largas barbas como aletas dorsales, y la cabrilla melera tiene rayas de color miel.

En cuanto a los nombres religiosos, en algunos animales pueden rastrearse formaciones debidas a su expresividad maléfica (García Mouton 1987: 192). Este es el caso del conejo diablo, perteneciente a la categoría de nombres religiosos, con un aspecto infernal: cuerpo anguiliforme, negro y enorme boca provista de afilados dientes. Respecto a gallo de San Pedro, se le compara con el gallo que, según la Biblia, cantó después de que San Pedro negara a Jesús tres veces ${ }^{37}$. Efectivamente, la especie denominada gallo de San Pedro se parece a un gallo por las largas aletas dorsales que recuer-

35 'Manta raída de que se sirven los pobres'. Parece derivado del castellano antiguo ruano 'hombre de guerra que no era hidalgo, caballero ni escudero', hasta 1300, de donde 'plebeyo, ordinario'. Este debe ser derivado del antiguo rúa 'calle', ss. XII-XVI, procedente (como el francés rue, portugués rua) del latín ruga 'arruga' y vulgarmente 'calle' (Coromines 2009: 487). El color de este pez hacer recordar al de una manta vieja y raída.

${ }^{36}$ De tramoya, de trama. 1617 En las provincias del norte designa todavía la tolva del molino, y luego una palanca destinada a parar la marcha del mismo [sic.], de donde pasó a designar una máquina teatral, 1617, y luego 'ardid, maña', 1626 (Coromines 2009: 549).

${ }^{37}$ Mateo, capítulo 26, versículo 75. 
dan a la cresta de esta ave. Además, está dotada de una mancha redonda negra en la parte central del cuerpo para que sus depredadores lo confundan con el ojo y, al atacar, lo hagan sobre una zona menos vulnerable. Esta mancha asemeja las huellas de los dedos del santo, en las imágenes religiosas, para sacar la moneda de su interior.

En el caso de gata tramolla, sin embargo, no hemos sido capaces de encontrar un significado a esta metáfora.

\subsubsection{Metáfora de nombres de objetos}

En nuestra muestra hemos aislado un total de 66 peces que se metaforizan con nombres de objetos.

Existe un total de 41 nombres simples.

Veintitrés, con nombres de herramientas u objetos domésticos: aguja, agujón, barrilote $^{38}$, candil, cantarilla ${ }^{39}$, catalufa ${ }^{40}$, cazón $^{41}$, cinto, lija, machete (juv.), malla ${ }^{42}$ (juv.), manta, mantelina/mantellina ${ }^{43}$, pejeclavo, pejesierra, pejepeine, pejepipa, rasqueta $^{44}$, sierra, sopipa, tableta, tapaculo, zapata.

Cinco relativas a otros objetos o partes de objetos: arestín $^{45}$ (juv.), pez vela, raya ${ }^{46}$, rémora ${ }^{47}$, tramolla $^{48}$.

Ocho, a armas: bullón ${ }^{49}$, escopeta, espadarte, mojarra ${ }^{50}$, mugarra $^{51}$, peje espada, pejesable, sable.

Cuatro, a instrumentos musicales: castañeta ${ }^{52}$, guitarra, peje trompeta, tamboril.

${ }^{38}$ De barril, de origen prerromano e incierto (Coromines 2009: 67).

${ }^{39}$ Diminutivo de cántara, de cántaro, del latín cantharus 'especie de copa grande, de dos asas', y este del griego kantharos íd., propiamente 'escarabajo'. Actualmente, vasija de barro, sin baño, del tamaño y forma de una jarra ordinaria y boca redonda. (Real Academia Española; Coromines 2009: 107).

${ }^{40}$ Del italiano antiguo cataluffa, cierto paño fabricado en Venecia. Tejido de lana tupido y afelpado, con variedades de dibujos y colores, del cual se hacen alfombras (Real Academia Española).

${ }^{41}$ Hacia 1335. Origen incierto; es común al castellano con el portugués, catalán y dialectos francoprovenzales e italianos. De cazo, 'vasija de metal con un mango para manejarla' (Coromines 2009: 121).

${ }^{42}$ Según Alvar (1993: 225) proviene de la palabra portuguesa malha, mancha. Sin embargo, este pez se asemeja a una malla: es de color plateado y el dibujo de las escamas se asemeja al entramado de una malla.

${ }^{43}$ De mantel, del latín mantele 'toalla'. Cambiado en mandil por el árabe, pasó de éste al castellano mandil (Coromines 2009: 356).

${ }^{44}$ Planchuela de hierro de cantos afilados y con mango de madera, que se usa para raer y limpiar los palos, cubiertas y costados de las embarcaciones (Real Academia Española).

${ }^{45}$ De arista, s. XIV (ariesta). Del latín vulgar aresta, latín arista, 'arista de la espiga', 'espina de pescado' (Coromines 2009: 42).

${ }^{46}$ Del latín raja (Coromines 2009: 467).

${ }^{47}$ Del latín remóra, cualquier cosa que detiene, embarga o suspende (Real Academia Española).

${ }^{48}$ Tramoya, de trama. Máquina para figurar en el teatro (Real Academia Española).

${ }^{49}$ (Der. del latín bulla 'bola'). 3. Especie de cuchillo usado antiguamente (Real Academia Española). Tenía bolas en el extremo de la empuñadura, de ahí el nombre de bullón.

${ }^{50}$ Pez de cuerpo comprimido, 1676 (almojarra), antes muharra 'punta de hierro de la lanza', 1728. Probablemente del árabe muharrab 'afilado' participio pasivo de harrab 'aguzar' (Coromines 2009: 375).

${ }^{51}$ De mojarra. 


\section{Uno, a ropa: peto.}

En cuanto a los nombres mixtos, hemos hallado 25.

Dieciséis en los que se combinan nombre de objeto + aspecto físico: aguja azul, aguja basta, aguja blanca, aguja fina, aguja paladar, carpa dorada, carpa roja, cazón dientuso, peje espada picudo, pejesable negro, raya picuda, tamboril azul, tamboril espinoso, tamboril negro, tamboril verde, tamboril chato.

Dos, nombre de objeto + lugar procedencia: cazón de altura, tamboril de hondura.

Dos, nombre de objeto + etnia: cazón moro, zapata morisca.

Uno, nombre de parte de objeto + objeto: raya de clavos.

Uno, nombre de objeto + calificativo animal: aguja mular.

Uno, nombre de objeto + personalidad: aguja volona.

Uno, nombre de objeto + rango: bullón/buyón real.

Uno, nombre de objeto + nombre de persona: aguja sara.

Al igual que en el caso de los peces que se bautizan con el nombre de otro animal, en el fondo, a los que se les atribuye un nombre de objeto siguen haciendo referencia a su aspecto físico: una especie se designa por el objeto al que se asemeja. Por ejemplo, los peces agujas son largos, finos y con la cabeza puntiaguda, la castañeta se parece en forma y tamaño a una castañuela, etc.

\subsubsection{Metáfora de personalidad}

La siguiente categoría con mayor número de metáforas es la de personalidad, con un total de 51. De estos, 34 son nombres simples y 17 compuestos o mixtos. Veamos los nombres simples.

Diecinueve nombres de aspectos negativos de personalidad o acciones negativas: baboso, chacarona ${ }^{53}$, chifleta ${ }^{54}$ (juv.), chupasangre, chupón, fula ${ }^{55}$, funfurriña ${ }^{56}$, hediondo/ jediondo, loquillo (juv.), marrajo ${ }^{57}$, pegador, picón, pejebobo, peje tostón, roncador, ronco, rufiana, tuna ${ }^{58}$, voraz/goraz.

${ }^{52}$ De castañuela. Diminutivo de castaña del latín castanea íd., derivado del griego kastanon íd (Coromines 2009: 117).

${ }^{53}$ De chacharón, charlatán (Real Academia Española).

${ }^{54}$ De chiflado.

${ }^{55}$ Lusismo (Alvar 1975: 432) que significa 'enojado, colérico'.

${ }^{56}$ De fanfurriña: Enojo leve y pasajero (Real Academia Española).

57 'Astuto, disimulado', 1609; 'especie de tiburón', 1616. Quizá de un nombre familiar del gato, como morro, morrongo, catalán marruixa, francés marlou: voces todas de creación expresiva (Coromines 2009: 359). Dicho de un toro o de un buey: Que astutamente arremete maliciosamente a golpe seguro (Real Academia Española).

58 'Vida holgazana y vagabunda', del antiguo argot francés tune (Coromines 2009: 561). También podría venir de la palabra inglesa para atún, tuna, pues este nombre corresponde a una especie de atún. 
Nueve relativas a realizaciones/recepción de acciones: pégalo, peje roba, pescada, pescadilla, rascancio ${ }^{59}$, rascacio, sama, tembladera, tembladora.

Seis aspectos positivos de la personalidad: cantarero, galán/a, guachinango/a (juv. $)^{60}$, guachilong $a^{61}$, peje volador, volón.

En cuanto a los nombres mixtos, hemos aislado los siguientes 17 nombres:

Nueve en los que se combinan rasgo de personalidad + aspecto físico/parte del cuerpo: fula amarilla, fula ancha, fula blanca, fula canela, fula colorada, fula negra, rascacio negro, rascagote ${ }^{62}$ (juv.), sama dorada.

Tres, personalidad + lugar de procedencia: fula de altura, fula de hondura, sama roquera.

Dos, personalidad + personalidad: peje tostón volador, sama guachinanga.

Uno, personalidad + objeto: sama zapata.

Uno, personalidad + rango: sama de ley.

Uno, personalidad + objeto/terminología marinera: pegatimón.

De nuevo comprobamos la gran riqueza de la creación metafórica por la que un pez es denominado por la forma en la que el pescador considera que actúa. Así, por ejemplo, se denomina marrajo a una especie de tiburón, por ser un animal astuto que arremete maliciosamente contra sus presas; sama proviene de brama, por el sonido que hace el pez (Viera y Clavijo 1982), etc.

\subsubsection{Metáfora de profesiones y actividades humanas}

Hay un total de 27. Nombres simples existen 18:

Siete de actividades profesionales diversas: escolar, herrera, pez piloto/peje piloto, tintorera, tonelero, trompetero, tronelero.

Tres actividades reales: jaqueta ${ }^{63}$, jaquetón $^{64}$ y pejerrey.

Siete de actividades religiosas: abade ${ }^{65}$, abadejo, abae, obispo, peje obispo, romerete, romero.

Una de actividad militar: soldado.

Nombres compuestos encontramos nueve:

\footnotetext{
${ }^{59}$ De rascacio.

${ }^{60}$ Voz mahua (en Cuba y Puerto Rico). Astuto, zalamero.

${ }^{61}$ Viene de guachinanga.

${ }^{62}$ Unión de rasca y cogote.

${ }^{63}$ Regresión de jaquetón, 'rey' (Alvar 1975: 454).
}

${ }^{64}$ Aumentativo de jaque. Del árabe clásico šăh, y este del persa šăh, rey (Coromines 2009: 320). Alvar (1975: 454) corrobora esta etimología con otras fuentes. Este tiburón es el rey del mar por su fuerza y envergadura.

${ }^{65}$ Este nombre y el de abae proceden del portugués (Alvar 1993: 218). De abad, del latín abbas, abbatis y éste del arameo abba 'padre' Pasando por el griego; abate es variante de empleo afrancesado o italianizante (Coromines 2009: 1). 
Cuatro en los que se combinan actividad humana + actividad humana: abade capitán, abade coronel, romero capitán, romero jefe.

Tres, actividad humana + aspecto físico/parte del cuerpo: escolar negro, escolar rasposo, romero de vieja.

Uno actividad humana + lugar procedencia: romero de hondura.

Uno actividad humana + raza/etnia: escolar chino.

Los nombres que tienen que ver con una profesión se eligen bien porque la especie podría tener alguna similitud con ese profesional o porque su actitud pueda recordarlo o porque alguna parte del pez recuerde a un instrumento típico de esa profesión. Por ejemplo, el pez denominado soldado posee un colorido que hace pensar en un soldado de infantería con su ropa de camuflaje; el obispo es un pez manta cuyas aletas al nadar parecen la casulla de un obispo, etc.

\subsubsection{Metáfora de nombres de persona}

Solo hemos encontrado 15 peces en esta categoría.

Trece nombres simples: alfonsito, alfonso, alfunsiño, antoñito, catalineja (juv.), catalineta (juv.), carmelita, charita (juv.), maría francisca (juv.), marlín, panchito ${ }^{66}$, panchona (juv.) ${ }^{67}$, sara.

$\mathrm{Y}$ dos nombres compuestos en el que se combinan nombre de persona + animal: alfonsiño pachón ${ }^{68}$, carmelita cocodrilo.

Según Alvar (1993: 159), «un mundo oscuro de superstición y temores ancestrales ha hecho que el hombre trate de granjearse la simpatía de las bestezuelas que le amedrentan o que le pueden hacer daño». Así, señala que el denominar a seres vivos con nombres de personas ayuda a disipar este miedo y 'caer simpático' a los animales, y da el ejemplo del nombre de pez catalineta. Sin embargo, García Mouton (1987: 195) contradice totalmente este punto. Sus estudios demuestran que se da nombre de persona a los animales benéficos, que se les considera mensajeros de Dios, que reciben rimas infantiles, que son capaces de predecir un buen acontecimiento. Pone el ejemplo del insecto Coccinella septempunctata, al que se conoce como: catalina, mariíca, marieta, margarita, teresina, martinica, conchita, pablilla, paquita, etc.

A pesar de la afirmación de Alvar, los peces que se han denominado en Canarias con el nombre de una persona están catalogados en Fishbase como inocuos o inofensivos para el hombre. En cuanto a su aspecto amenazante, existen cuatro especies de esta índole: la carmelita (denominada también culebra), que tiene aspecto de serpiente; la carmelita cocodrilo, que tiene la cabeza como este reptil; y marlín y sara que son peces aguja y, por tanto, pueden causar temor. El resto de las especies no nos han parecido especialmente desafiantes. Las que atienden a los nombres comunes de alfonsito, alfonso, alfunsiño, antoñito destacan por su pequeño tamaño y unos ojos saltones muy desarrollados con

\footnotetext{
${ }^{66} \mathrm{Al}$ igual que el nombre pachón podría también provenir de perro-pachón (Alvar 1977: 237).

${ }^{67}$ Véase la nota anterior.

${ }^{68}$ El nombre pachón proviene de perro-pachón (Alvar 1977: 237).
} 
respecto a la cabeza. Quizá esto pueda producir una cierta inquietud. El nombre de panchito es el común de dos especies, una de las cuales está constituida por hermosos ejemplares de alegre colorido rosa y lila. Por lo tanto, aquí se podría aplicar lo investigado por García Mouton: sería un pez al que se le pueden atribuir beneficios.

\subsubsection{Metáfora de nombres de plantas}

En la categoría de plantas o partes de plantas hay un total de siete. De estos, cuatro son nombres simples: alelía ${ }^{69}$, brota $^{70}$, lirio, pámpano ${ }^{71}$.

Tres son nombres compuestos:

Dos en los que se combinan planta + raza/etnia: pámpano chino, pámpano morisco.

Uno, planta + lugar de procedencia: brota de tierra.

Una vez más, el aspecto del pez prima para crear una metáfora. A la especie alelía, sin embargo, que es un lenguado pintorriado, no le encontramos ninguna semejanza ni forma de vincularlo con el alhelí. La brota vive en oquedades en fondos arenosos o fangosos, por lo que, al asomar la cabeza y dado su color parduzco, puede recordar a un brote que sale de la tierra o de la cueva. El lirio posee un color blanco plateado que podría emular al de esta flor. Por último, a las cuatro especies que se conocen con el nombre común de pámpano, tampoco les hemos encontrado ninguna similitud con la hoja de la vid. Pámpano chino y pámpano morisco son los apodos de una misma especie. Como es un pez muy extendido por el mundo, se encuentra tanto en China como en los países árabes. Tampoco, sin embargo, tiene similitud física con la hoja de la vid.

\subsubsection{Metáfora de terminología marinera}

Es curioso que a pesar del íntimo contacto con la terminología marinera por parte de los pescadores, solo se han formado cinco nombres por esta metáfora.

En concreto hay tres nombres simples: guelde ${ }^{72}$, anguila ${ }^{73}$, tarrafilla $^{74}$ (juv.).

De los compuestos contamos con dos:

Uno en el que se combinan término marinero + característica física: guelde blanco.

Uno, término marinero + actividad humana: anguila jardinera.

${ }^{69}$ De alhelí, del árabe heiri o hiri íd (Coromines 2009: 23).

${ }^{70}$ De brote del gótico brut íd. (hermano del alemán antiguo broz íd., y pariente del alemán sprosse íd., inglés sprout 'brotar') (Coromines 2009: 88). Según Alvar (1975: 445), se trata de un lusismo.

${ }^{71}$ Del latín pampinus, 'hoja de la vid' (Coromines 2009: 410).

${ }^{72}$ De gueldo 'Cebo que emplean los pescadores, hecho con camarones y otros crustáceos pequeños’ (Real Academia Española).

${ }^{73}$ Del latín anguilla íd; en su forma actual el vocablo parece tomado del catalán, cuya fonética corresponde; la forma propiamente castellana anguilla fue predominante hasta el s. XVII y todavía se oye en la mayor parte de América, pero fue reemplazada por aquélla por hallarse en tierras de lengua catalana las bocas de los ríos Ebro, Llobregat, Turia y Júcar, que es donde más abunda la anguila (Coromines 2009: 33). Cada uno de los dos largos maderos, paralelos a la quilla del buque en construcción, que, con otras piezas, constituyen la base sobre la que se bota este al agua desde la grada (Real Academia Española).

${ }^{74}$ Diminutivo de tarrafa, arte de pesca tipo cerco (Real Academia Española). 
Guelde es un vasquismo (Alvar 1975: 461) que da nombre a dos especies que son fácilmente capturables con este cebo, pues se alimentan principalmente de pequeños crustáceos y moluscos. Anguila hace referencia al aspecto físico del pez, que podría asemejarse a un madero largo. Tarrafilla es el diminutivo de tarrafa, un arte de pesca tipo cerco. Este nombre se emplea para el ejemplar juvenil (de ahí probablemente el uso del diminutivo) de una especie que se captura con esta arte.

Guelde blanco es la denominación de una de las especies de guelde. Se añade blanco para distinguirlo de la otra especie que es multicolor.

La anguila jardinera tiene, efectivamente, forma de palo y habita en fondos arenosos en los que solo asoma la cabeza y parte del cuerpo y se oculta totalmente cuando se siente atemorizada. Como vive en colonias, el aspecto que ofrecen varios ejemplares juntos es el de un jardín. De ahí que se la pueda considerar "jardinera".

\subsubsection{Metáfora de lugar de procedencia}

También hay cinco. Tenemos cinco simples: pedregal, roquera, sarda y tollo ${ }^{75}$.

Y uno compuesto: lugar de procedencia + profesión: marismero-palanquín ${ }^{76}$ (juv.).

Estas denominaciones se emplean en clara referencia con el lugar donde habita el animal. Dos de los nombres son, sin embargo, dudosos en su formación metafórica. Sarda, natural de Cerdeña, corresponde a cinco especies distintas de tiburón que se pueden encontrar en esta isla, así como en muchas otras partes del mundo. Según Viera y Clavijo (1982: 397) podría venir del nombre inglés shark, tiburón, lo que nos parece más plausible que la explicación anterior. El marismero-palanquín vive en marismas, pero no hemos podido resolver qué vinculación podría tener con un palanquín.

\subsubsection{Metáfora de estado civil/sexo}

En esta categoría incluimos aquellos nombres que aluden al sexo (hombre o mujer) o al estado civil (casado, soltero).

Hay cinco. Tres simples: doncella, machuelo ${ }^{77}$, señorita.

$\mathrm{Y}$ dos mixtos en los que se combinan: sexo/rango + lugar de procedencia: doncella de hondura, y sexo+ pertenencia: macho de morena.

Alvar (1977: 237) señala que el pez doncella se llama así en clara referencia a su belleza. A esta especie se la conoce también como señorita. El macho de morena es el pez que más aspecto tiene de ser del sexo masculino dentro de todas las especies de

${ }^{75}$ Vasquismo. Alvar (1993: 177-187) nos dice que su etimología no es clara. Podría tener su origen en el celta tullón 'hueco, hoyo, agujero'. Según (Coromines 2009: 543), es de origen incierto, pero quizá provenga de 'hoyo', voz regional del nordesde y el noroeste, hermana del calalan toll 'poza en un río o estanque', 'balsa'. El tiburón de esta especie se conoce con este nombre por los lugares cenagosos donde habita.

76 'Andas empleadas en Oriente', s. XIX. Del portugués palanquim, y éste del hindostánico palaki íd., que viene del sánscrito paryankah 'cama' (Coromines 2009: 408). 1. Ganapán o mozo de cordel que leva cargas de una parte a otra. 2. Mar. Cada uno de los cabos que sirven para cargar los puños de las velas mayores, llevándolos a la cruz de sus vergas respectivas (Real Academia Española).

${ }^{77}$ De macho. 
morenas, pues tiene una cabeza ancha y grande. En cuanto al machuelo, es la más grande y ancha de las especies de sardinas, por lo que puede parecer el macho.

\subsubsection{Metáfora de nombres religiosos}

Cuatro son los nombres relativos a religión: angelote, peje diablo, pez/ peje ángel, janequín ${ }^{78}$.

Aquí nos encontramos con dos tipos de nombres: los divinos y los diabólicos.

Los divinos, según García Mouton (1987: 195) se adjudican a animales que se consideran benéficos, de Dios. En el caso de nuestra especie de pez que se conoce con los nombres de angelote y ángel, las aletas se asemejan a unas alas que parece que bate cuando nada.

En cuanto a los nombres diabólicos, son característicos de animales a los que se les achaca un poder maléfico (ibid.: 192) o que, según la creencia popular, encarnan al mismísimo Belcebú. Este es el caso del peje diablo y el janequín. El peje diablo es un pez negruzco, feo y con unos ojos saltones, como se podría identificar a un demonio. El janequín es una especie de tiburón y ya de todos es conocida su mala fama de animal endemoniado: taimado, feroz y asesino.

\subsubsection{Metáfora de mundo celeste}

Hay tres, de los cuales solo uno es simple: peje luna.

Dos son compuestos:

Uno en el que se combinan mundo celeste + procedencia: luna de mar, y otro, mundo celeste + rango: pez luna real.

Con el nombre de luna se ha bautizado a las especies que tienen forma de luna creciente.

\subsubsection{Metáfora de nombres de frutas}

Solo tenemos dos casos que se han formado por metáfora con el nombre de una fruta: albacora $^{79}$, gambusino ${ }^{80}$ (juv.).

El gambusino se puede llamar así, pues al igual que esa variedad de pera, tiene una mancha amarrilla distintiva en cada escama de la mitad superior del cuerpo, lo que le confiere un efecto de rayas amarillentas. Además tiene tintes de amarillo en la zona interorbital y en el labio superior. También puede que se le llame así, pues se utiliza como cebo para otras especies y, en este caso, se podría asemejar una vez desmenuzado al gambusín o gambusino (Upogebia Pusilla), una especie de gamba.

\footnotetext{
${ }^{78}$ Según Alvar (1993: 198-199) janequín proviene de una leyenda difundida en Francia en el siglo XII de la maisnie Halequin. Los herlequins eran diablos burlones que practicaban ejercicios acrobáticos.

${ }^{79}$ Del árabe hispano albakúra, y este del árabe clásico bākūrah 'fruta temprana', breva (fruto de la higuera) (Real Academia Española).

${ }^{80}$ De gambusina, variedad de pera (en Murcia) (Real Academia Española).
} 
El nombre albacora, por su parte, bautiza a dos especies de atún que no se asemejan para nada a una breva, así que no podemos determinar el origen de este nombre por esa metáfora.

\subsubsection{Metáfora de nombres de sabores}

De esta última categoría solo hay uno simple: agriote. Y otro mixto, en el que se combinan parte del cuerpo + sabor: bocadulce.

Este último nombre se asigna a un tiburón. Quizá venga dado por ese afán de adular a las especies que nos producen temor.

En cuanto a agriote, su carne es muy apreciada, pero no es de sabor agrio, por lo que no hemos encontrado una motivación para esta metáfora.

\subsubsection{Metáfora con nombre de órgano sexual}

Hay uno compuesto: parte sexual + rango: carajillo real.

Carajillo es un diminutivo de carajo, metáfora sexual del nombre del miembro viril por el carácter alargado del pez. Corresponde a un pez que posee, además, una tonalidad irisada que le puede dotar de ese halo de realeza.

\subsubsection{Metáfora de parentesco}

Solo hay un nombre compuesto: parentesco + pertenencia/parte del cuerpo: madre de la boga.

El pez boga y la especie conocida como madre de la boga son muy similares. Sin embargo, el primero mide como máximo $13 \mathrm{~cm}$ y el segundo, 34, por lo que podría parecer su madre.

\section{COMPARACIÓN DE RESULTADOS}

Al comparar nuestros resultados con los estudios anteriores de la metáfora en los ictiónimos de Canarias, solo hemos hallado un autor que aborda este tema. Se trata de Alvar Ezquerra (1977: 233-267), quien analiza la metáfora en la ictionimia del comentado diccionario de Viera y Clavijo. Afirma que diez nombres de las 100 especies que engloba el diccionario provienen de nombres de animales terrestres (burro, conejo, gata, araña, caballa, cabrilla, ratón, perro, chucho, pachona y baqueta), pero no los divide en grupos (ej.: insectos, animales domésticos, etc.) y señala como grupo distinto el de la ornitología con dos nombres (palometa y corvina), aunque reconoce que debería incluirse en el de animales terrestres. El grupo más numeroso es el de las denominaciones que tienen que ver con alguna peculiaridad física de los peces. Da 13 ejemplos de este grupo y los divide en tres subcategorías. 1) Nombres que realzan la belleza del animal: bonito, galana, doncella. 2) Nombres relativos al color: dorado, rubio, morena, pejeverde. 3) Nombres que destacan alguna peculiaridad física: barrigudo, dentón, berrugate, goraz, lenguado, roncador. Sin embargo, dentro de este último grupo, goraz y roncador no tienen que ver con aspecto físico sino con el comportamiento del animal. No indica si hay más nombres relacionados con el aspecto físico, 
como tampoco lo hace de las metáforas que hacen referencia a actividades del hombre (tres nombres: escolar, romero, herrera), su dignidad (pejerey) o su aspecto físico (vieja). No queda claro que considere un grupo distinto de aspecto físico con un solo ejemplo, vieja, diferente del de peculiaridades físicas. Deberían fundirse en una única categoría. Del reino vegetal sí dice que solo ha hallado dos (lirio y pámpano) y del mundo celeste una (luna de mar). De las artes bélicas menciona tres denominaciones (peje armado, peto y espadarte); del mundo eclesiástico, dos (peje ángel y abadejo) y otras tantas de nombres de instrumentos musicales (castañeta, peje tamboril), y cinco (aguja, lija, manta, martillo, peje cofre) de herramientas, utensilios y objetos.

Por tanto, el estudio de Alvar Ezquerra resulta un tanto difuso, ya que no realiza una clasificación exhaustiva, ni determina el número exacto de nombres que se incluirían en cada grupo.

Nuestra investigación, sin embargo, abarca todos los nombres vernáculos posibles encontrados en documentos relevantes publicados en los últimos quince años. Es, por tanto, más amplia, más actual, y proporciona todos los nombres clasificados por metáfora en diferentes categorías. Sin embargo, en nuestros documentos de vaciado no hemos encontrado tres nombres recogidos por Viera y Clavijo y comentados por Alvar: peje cofre, martillo y peje armado.

\section{CONCLUSIONES}

No existen obras lexicográficas o ictiológicas que recojan un listado completo y actualizado de ictiónimos de Canarias. Con nuestra investigación hemos intentado paliar este vacío, pues hemos registrado todos los ictiónimos encontrados en una selección de obras prestigiosas publicadas en los últimos trece años.

Además, hemos analizado la metáfora y con ellos revelamos la profunda representación imaginativa de la lengua. Hemos aislado 737 especies de peces que habitan en aguas de Canarias. De estas, 279 especies cuentan con nombre común en Canarias y son nombradas por metáfora con 366 nombres distintos $(80,97 \%$ del total de denominaciones). El grupo que alberga el mayor número de metáforas es el de aspecto físico $(24,86 \%)$, aunque en realidad prácticamente todas las categorías hacen referencia de uno u otro modo al aspecto físico del pez. Hemos hallado, además, las siguientes categorías: animales $(22,13 \%)$, objetos $(18,03 \%)$, personalidad $(13,94 \%)$, profesiones/actividades humanas $(7,38 \%)$, nombres de persona $(4,1 \%)$, plantas $(1,91 \%)$, terminología marinera $(1,37 \%)$, estado civil/sexo $(1,37 \%)$, lugar de procedencia $(1,37 \%)$, nombres religiosos $(1,09 \%)$, mundo celeste $(0,82 \%)$, frutas $(0,55 \%)$, sabor $(0,55 \%)$, órgano sexual $(0,27 \%)$ y parentesco $(0,27 \%)$.

En algunos casos es difícil esclarecer cómo ha surgido la metáfora. «La motivación antigua se oscurece, porque el hablante actual ya no tiene el mismo tipo de conciencia de la realidad y ha perdido, en muchos casos, los apoyos que la imaginación colectiva prestaba a esos nombres» (García Mouton 1987: 197). Así, no hemos encontrado explicación para la metáfora de los nombres vernáculos gata tramolla, albacora, marismero-palanquín, sarda y agriote. 
Con nuestra muestra pretendemos llevar a cabo en un futuro otras investigaciones de especial interés. Por un lado, planeamos comprobar de todos estos ictiónimos cuáles han sido creados realmente en Canarias. Por otra parte, pretendemos verificar la concordancia o divergencia de los nombres vernáculos hallados en los distintos documentos de vaciado que hemos empleado, para determinar si, como recrimina Alvar (1993: 185), existen incoherencias tanto en los libros de ictiología como en los repertorios lexicográficos de esta materia. También será relevante estudiar y relacionar todos los nombres vernáculos formados por metáfora con los que se designa a cada especie. Por último, podríamos determinar la percepción del género gramatical: por qué unos nombres son masculinos y otros femeninos.

\section{REFERENCIAS BIBLIOGRÁFICAS}

Academia Canaria de la Lengua (2013): Diccionario de la Academia Canaria de la Lengua, en: www.academiacanarialengua.org/diccionario/ [fecha acceso: 10.07.2012]

ARNZT, Reiner y Heribert PICHT (1995): Introducción a la Terminología, Madrid, Fundación Germán Sánchez Ruipérez.

Alvar, Manuel, ed. (1968): Estudios Canarios, I, Las Palmas de Gran Canaria, Cabildo Insular de Gran Canaria.

(1975): «La terminología canaria de los seres marinos», en Anuario de Estudios Atlánticos, 21, pp. 419-469.

- (ed.) (1977): Actas del V Congreso Internacional de Estudios del Mediterráneo, Las Palmas de Gran Canaria, Cabildo Insular de Gran Canaria.

(ed.) (1993): Estudios Canarios II, Madrid, Viceconsejería de Cultura y Deportes, Gobierno de Canarias.

AlVAR EZQUERRA, Manuel (1977): «La ictionimia en el Diccionario de Historia Natural de Viera y Clavijo», en M. Alvar, ed., Actas del V Congreso Internacional de Estudios del Mediterráneo, Las Palmas de Gran Canaria, Cabildo Insular de Gran Canaria, pp. 233-267.

BRITo HeRnÁnDEZ, Alberto et al. (2002): Peces de las Islas Canarias: catálogo comentado e ilustrado, La Laguna, Francisco Lemus.

Consejería de Agricultura, Ganadería, Pesca y Aguas del Gobierno de Canarias (2012): Especies de interés pesquero de Canarias, en: www.gobiernodecanarias.org/agricultura/pesca/especies/default.htm [fecha de acceso: 04.06.2012]

CONSEJERÍA DE Medio AMBIENTE y ORDENACIÓN TERRITORIAL DEL GobIERNo DE CANARIAS (2003): Listado de Especies Marinas de Canarias: Algas, Hongos, Plantas y Animales, en: http://www.gobiernodecanarias.org/medioambiente/piac/AlfrescoFileTransferServlet?acti on=download\&ref=e710612f-139e-4e5f-9300-8eb7868ed026 [fecha de acceso: 04.04.2013]

COROMINES, Joan (2009): Breve diccionario etimológico de la lengua castellana, $3^{\mathrm{a}}$ ed. muy revisada y mejorada, Madrid, Gredos. 
Cuvier, Georges y Achille Valenciennes (1828-1849): Histoire Naturelle des Poissons, Paris-Strasbourg, 22 vol.

Departamento de Biología Pesquera del instituto Canario de Ciencias Marinas (2013): Pescabase. Documento en: www.pescabase.org [fecha de acceso: 05.06.2012].

FRANQUET SANTAELla, Fernando (1995): Especies de interés pesquero de Canarias, Canarias, Consejería de Pesca y Transportes.

Froese, Reiner y Daniel Pauly, eds. (2013): FishBase World Wide Web electronic publication, en: www.fishbase.org [fecha de acceso: 05.06.2012].

GARCíA MOUTON, Pilar (1987): «Motivación en nombres de animales», Lingüistica española actual, 9/2, pp. 189-198.

GonZÁlez JimÉNEZ, José Francisco et al. (2000): Peces de Canarias: guía submarina, $5^{\mathrm{a}}$ ed., La Laguna, Francisco Lemus.

HANQuet, Sergio (2004): 100 peces de Canarias, Santa Cruz de Tenerife, Hanquet.

Machado CARrillo, Antonio y Marcial Morera PÉREZ, coord. (2005): Nombres comunes de las plantas y los animales de Canarias, La Laguna, Academia Canaria de la Lengua.

Ministerio de Medio Ambiente y Medio RuRAl Marino del Gobierno de España (6 abril 2011): «Listado de denominaciones comerciales de especies pesqueras y de acuicultura admitidas en España», Boletín Oficial del Estado 82/III, pp. 35515-35544.

MONDÉJAR, José (1982): «Congrio y zafío: un capítulo de ictionimia mediterránea y atlántica», Vox romanica , 4, pp. 206-219.

MonTERde REY, Ana María (2005): «GeneSis frente a otros programas informáticos generadores de sistemas de conceptos», en Laura Cruz García et al., eds. Traducir e interpretar: visiones, obsesiones y propuestas, Las Palmas de Gran Canaria, Universidad de Las Palmas, pp. 83-106.

(2006): «Genesis: Programa informático dirigido a estudiantes de Terminología para la generación de sistemas de conceptos», en Heribert Picht, ed. Modern Approaches to Terminological Theories and Application, Bern-Berlin-Bruxelles-Frankfurt am Main-New York-Oxford-Wien, Peter Lang, pp. 301-327.

(2011): «Informática al servicio de la terminología y la traducción: el diseño de sistemas de conceptos», ReCIT: Revista del Área de Traductología (Ex Centro de Investigación en Traducción), 2, pp. 51-65.

VENY, Joan (1993): «Origine de l'ichtyonyme hispanique baila 'dicentrrarchus punctatus'», en G. Hilty, ed., Actes du XXe Congrès International de linguistique et Philologie Romanes, 6-11 avril 1992. Université de Zurich, Tübingen, Francke, IV, pp. 761-774.

Viera y ClaviJo, José (1982): Diccionario de Historia Natural de las Islas Canarias, edición dirigida y prologada por Manuel Alvar, Las Palmas, Mancomunidad de Cabildos. 